\title{
SIMULASI GETARAN BERBASIS METODE ELEMEN HINGGA MENGGUNAKAN SOFTWARE ANSYS UNTUK MENGIDENTIFIKASI KONDISI KOMPONEN UTAMA TURBIN GAS SIEMENS $V$ 94.2 EMPAT TINGKAT SEBAGAI PEMBANGKIT LISTRIK
}

\author{
Ikhwansyah Isranuri, Muhammad Firdaus \\ Departemen Teknik Mesin Fakultas Teknik Universitas Sumatera Utara \\ firdaus150797@gmail.com
}

\begin{abstract}
ABSTRAK
Getaran menjadi salah satu sinyal utama dalam menganalisis kondisi suatu permesinan. Getaran memiliki peranan penting dalam mengetahui kondisi kesehatan permesinan. Penelitian ini bertujuan untuk memproyeksikan deformasi total, regangan elastis normal, tegangan normal dan mengetahui putaran kritis poros turbin. Dan untuk Menganalisa vibrasi yang terjadi pada sudu kompresor. Dalam penelitian ini digunakan turbin gas siemens v 94.2 empat tingkat. Simulasi dilakukan dengan menggunakan software ANSYS Workbench 18.1 dan software Solidworks 2015 untuk proses penggambaran tiga dimensi. Dalam proses simulasi digunakan dua kecepatan putar yaitu $3000 \mathrm{rpm}$ dan $5000 \mathrm{rpm}$ dengan pemberian beban dinamis dari tiga sumbu dan di pengaruhi oleh gaya gravitasi. Pemilihan material dari kompresor ini adalah baja, proses design digunakan dalam bentuk solid. Dari hasil perbandingan simulasi diperoleh deformasi total, regangan elastis normal, tegangan normal pada kecepatan 3000 rpm pada tiap arah pembebanan adalah sama. Begitu pula pada kecepatan $5000 \mathrm{rpm}$. Hal ini diakibatkan karena beban yang diberikan terlalu kecil untuk mempengaruhi perubahan total deformasi, normal stress dan normal elastic strain. Frekuensi pribadi turbin gas empat tingkat pada kecepatan putar $3000 \mathrm{rpm}$ dan 5000 rpm mendekati frekuensi kerja.
\end{abstract}

Kata kunci: Simulasi getaran, Turbin gas siemens v 94.2, Software ANSYS, Turbin, Frekuensi.

\section{PENDAHULUAN}

Kebutuhan akan penggunaan energi listrik mengalami peningkatan sebandingkan dengan nilai pertumbuhan penduduk. Perusahaan Listrik Negara (PLN) hadir sebagai salah satu solusi dalam penyedian energi listrik. Penelitian ini dilakukan untuk menganalisa hasil dari data maintenance pada turbin gas empat tingkat pada pembangki listrik di Sumatera Utara

Turbin gas merupakan salah satu komponen pada pembangkit bertenaga uap, didalam turbin gas terbagi lagi dalam beberapa komponen yaitu turbin, kompresor, combustion chamber dan generator. Pada tugas sarjana ini difokuskan untuk melakukan analisa pada turbin. Kondisi dari turbin sangat berpengaruh terhadap kinerja dari turbin gas karena turbin berfungsi untuk sebagai penggerak awal dari rangkaian turbin gas.

Analisis getaran digunakan sebagai alat diagnostik untuk memperkirakan kondisi dan kerusakan pada turbin. Karena turbin memiliki prinsip kerja rotasi, kondisi dan kerusakan dapat di deteksi dari frekuensi getaran yang terjadi pada turbin. Frekuensi tersebut didapatkan dengan melakukan pengecekan pada turbin yang dilakukan secara periodik. 
Pada tugas sarjana ini proses analisis dilakukan dengan bantuan software ANSYS, yaitu dengan melakukan simulasi getaran dengan frekuensi yang didapatkan dari pengukuran. Dari simulasi getaran (vibrasi) didapatkan kondisi dan titik terjadinya getaran yang melebihi batas izin getar sehingga mempermudah perawatan dan pemantauan kondisi dari turbin. Turbin yang dipergunakan pada tugas ini adalah turbin gas empat tingkat pada turbin gas siemens $\mathrm{v} 94.2$ yang terdapat pada pembangkit listrik tenaga uap (PLTU) belawan, sumatera utara

\section{TINJAUAN PUSTAKA}

Turbin gas merupakan peralatan pembakit tenaga dimana tenaga tersebut didapat dari ekspansi gas berkecepatan tinggi dan kemudian mendorong sudu- sudu yang langsung menghasilkan gerak putar pada rotornya. Putaran rotor tersebut nantinya dapat dimanfaatkan untuk memutar generator listrik. Turbin gas tersusun atas komponen-komponen utama seperti air inlet section, compressor section, combustion section, turbine section, dan exhaust section. Sedangkan komponen pendukung turbin gas adalah starting equipment, lube-oil system, cooling system, dan beberapa komponen pendukung lainnya.

Getaran adalah suatu peristiwa gerak bolak balik secara teratur suatu benda melalui satu titik seimbang. Karena terjadi dengan teratur, getaran sering juga disebut dengan gerak periodik. Kuat atau lemahnya pergerakan benda tersebut dipengaruhi oleh jumlah energi yang diberikan. Semakin besar energi yang diberikan maka semakin kuat pula getaran yang terjadi. Satu getaran sama dengan satu kali gerakan bolak balik penuh dari benda tersebut

Mechanical Vibration atau Getaran Mekanis merupakan suatu istilah yang kemunculannya telah melalui proses panjang. Untuk memahami getaran mekanis, orang terlebih dahulu harus memahami makna mekanika sebagai cabang ilmu pengetahuan, karena getaran merupakan salah satu fenomena dari mekanika. Tinjauan sejarah perkembangan mekanika dan getaran tidak lepas dari dua aspek, yaitu hukum alam dan rekayasa. Yang menarik dalam sejarah hukum alam dan rekayasa, apabila kita fokus pada runtuhnya peradaban Islam abad ke-3, hampir semua pakar mekanika terlebih dahulu membahas interpretasi hukum alam, aksioma, uraian, bahkan rumus matematika. Dan hal ini dilakukan terlebih dahulu sebelum membahas rekayasa, aplikasi, serta hubungan dari masing-masing hukum alam tersebut. Bahkan, tinjauan terhadap hukum alam pada abad ke-3 dilakukan sampai pada esensi yang paling dalam, yaitu filosofi.

Terdapat tiga parameter utama dalam pengukuran vibrasi terhadap sebuah mesin, yaitu : displacement, velocity dan acceleration yang harus diperhatikan sebelum menganalisa penyebab terjadinya vibrasi yang tidak normal. 
FEM adalah singkatan dari Finite Element Method, dalam bahasa Indonesia disebut Metode Elemen Hingga. Konsep paling dasar FEM adalah, menyelesaikan suatu problem dengan cara membagi obyek analisa menjadi bagian-bagian kecil yang terhingga. Bagian-bagian kecil ini kemudian dianalisa dan hasilnya digabungkan kembali untuk mendapatkan penyelesaian untuk keseluruhan daerah. Kata "finite atau terhingga" digunakan untuk menekankan bahwa bagian-bagian kecil tersebut tidak tak terhingga, seperti yang lazim digunakan pada metode integral analitik. Pembuatan mesh atau yg lebih dikenal dengan istilah meshing, merupakan salah satu langkah dalam pre-processing sebuah simulasi. Baik untuk simulasi struktural yg menggunakan Finite Element Method (FEM), maupun simulasi CFD yang umumnya menggunakan Finite Volume Method (FVM). Mesh ini sendiri berguna untuk membagi geometry dari model menjadi banyak elemen yang nantinya digunakan oleh solver untuk membangun volume kontrol

Solidwork adalah software yang digunakan untuk membuat desain produk yang sederhana hingga yang kompleks seperti roda gigi, cashing handphone, mesin mobil dan sebagainya. Solidwork menyediakan feature based, parametric solid modeling. Feature based dan parametric ini yang akan sangat mempermudah dalam membuat model 3D. Karena hal ini membuat kita sebagai user bisa membuat model sesuai dengan intuisi kita.Solidwork simulation memungkinkan anda untuk melakukan uji produk sebelum mulai dibuat, membantu mencegah kesalahan lebih awal pada proses desain. Aplikasi ini sangat berguna untuk analis FEA, namun cukup mudah untuk designers produk. Solidwork simulation bahkan bisa membantu anda untuk mengoptimalkan kinerja dan biaya desain anda dengan maksimal. Tidak perlu menunggu sampai produk dibuat untuk melakukan tes, atau membuat berbagai macam prototipe.

ANSYS adalah program paket yang dapat memodelkan elemen hingga untuk menyelesaikan masalah yang berhubungan dengan mekanika, termasuk di dalamnya masalah statik, dinamik, analisis struktural (baik linier maupun nonlinier), masalah perpindahan panas, masalah fluida dan juga masalah yang berhubungan dengan akustik dan elektromagnetik.

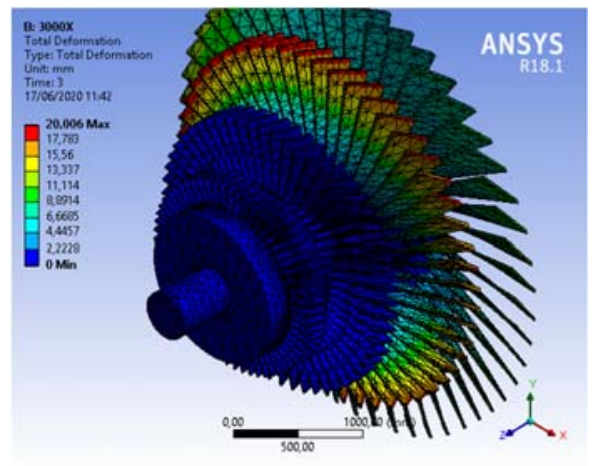

Gambar 2.1 Proses Simulasi dengan Software ANSYS 


\section{METODE PENELITIAN}

Tempat penelitian dilakukan di laboratorium Pusat Riset Noise and Vibration Control, Departemen Teknik Mesin Universitas Sumatera Utara. Pada penelitian ini, alat yang digunakan untuk melakukan pemodelan dengan menggunakan software Solidwork dan untuk melakukan simulasi menggunakan software ANSYS adalah laptop.

Proses penggambaran turbin gas empat tingkat ini dilakukan dalam bentuk 3D dengan menggunakan software Solidwork. Solidwork yang digunakan pada pemodelan skripsi ini yaitu solidwork 2015. Sedangkan data dimensi turbin gas empat tingkat siemen v 94.2 didapatkan dari PLTU Belawan, Sumatera Utara.

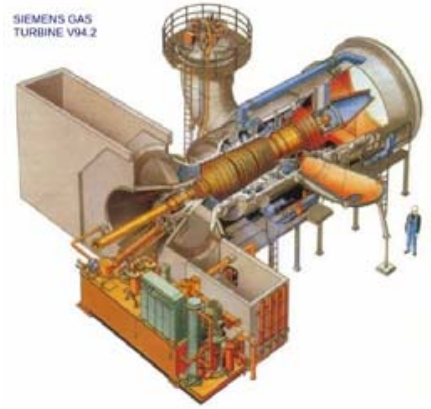

(a)

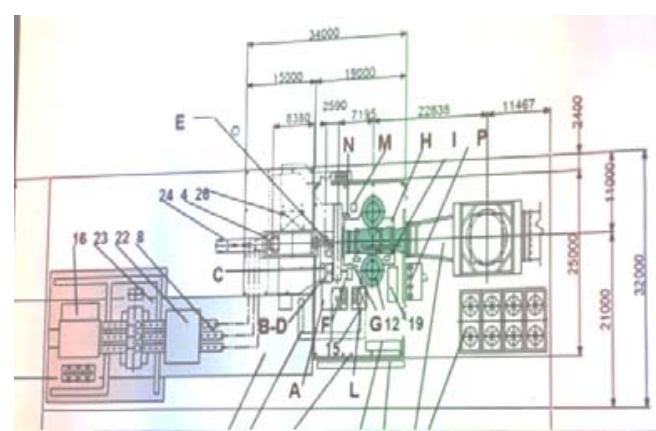

(b)

Gambar 3.1 (a) Turbin Gas Siemens v 94.2 (b) Gambar Kerja

Turbin Gas Siemens v 94.2

Proses simulasi digunakan menggunakan software ANSYS, adapun software ANSYS yang digunakan peneliti adalah software ANSYS 18.1. Proses simulasi yang digunakan yaitu simulasi statik struktural. Adapun proses simulasi dilakukan dengan Engineering data, berisi data dari material yang digunakan, karena material dari turbin gas siemens v 94.2 yaitu baja, selanjutnya Geometri, yang digunakan pada peneltitian ini adalah solid. Meshing bertujuan untuk membagi komponen komponen dalam bentuk sel sehingga memperjelas hasil komputasi, mempermudah proses komputasi, dan untuk membuat jaring-jaring atau ayakan pada kompresor. Adapun tipe meshing yang peneliti gunakan adalah Coarse (kasar), dengan bentuk tetrahedron dan memiliki panjang sisi paling kecil dengan ukuran $0,044 \mathrm{~mm}$.

Selanjutya support, bertujuan untuk mengekang atau tumpuan pada kompresor penelitian ini menggunakan displacement support. Salah satu parameter yang peniliti gunakan adalah memasukkan gaya gravitasi bumi. Parameter kecepatan putar (rotational velocity), kecepatan putar pada kompresor adalah $3000 \mathrm{rpm}$ dan $5000 \mathrm{rpm}$. Pembebanan yang diberikan adalah pembebanan dinamis dengan memberikan gaya (force) selama 3 detik. 
Berdasarkan hasil penelitian pada kecepatan putar $3000 \mathrm{rpm}$ nilai frekuensi natural pada ketiga sumbu hasilnya sama, frekuensi yang dihasilkan adalah $34,022 \mathrm{~Hz} ; 47,739 \mathrm{~Hz} ; 47,743$ Hz; 48,672 Hz.. Pada kecepatan putar 5000 rpm nilai frekuensi natural pada ketiga sumbu hasilnya sama, frekuensi yang dihasilkan adalah $37,537 \mathrm{~Hz} ; 66,377 \mathrm{~Hz} ; 66,406 \mathrm{~Hz} ; 78,309 \mathrm{~Hz}$.

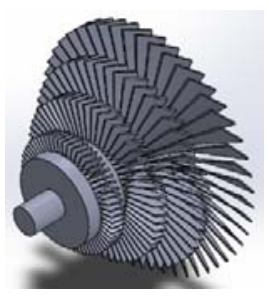

(a)

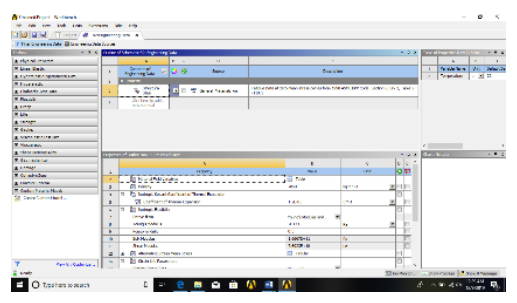

(b)

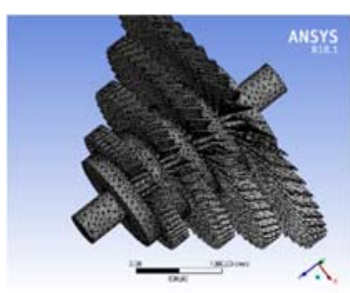

(c)

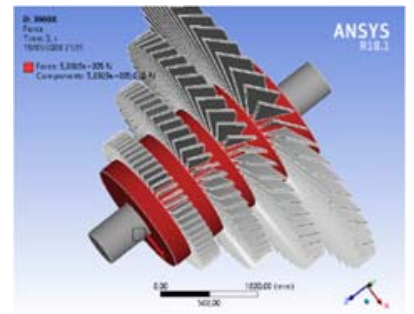

(d)

Gambar 3.2 (a) Gambar 3D turbin dengan solidwork, (b) Engineering data,

(c) Hasil meshing turbin, (d) Pembebanan pada turbin.

\section{HASIL PENELITIAN DAN PEMBAHASAN}

Pembuatan model 3D turbin empat tingkat mempunyai panjang $2900 \mathrm{~mm}$ dan diameter tie road $400 \mathrm{~mm}$. Dengan ukuran terbesar blade berdiameter $3600 \mathrm{~mm}$ dan blade terkecil berdiameter $1654 \mathrm{~mm}$. Hollow shaft berdiameter $1250 \mathrm{~mm}$. Desain turbin empat tingkat ini memiliki volume $3.165 .200 .000 \mathrm{~mm}^{3}$ dan memiliki massa $24847 \mathrm{~kg}$.

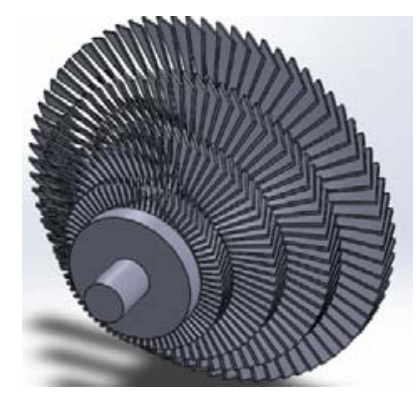

Gambar 4.1 Design 3D Kompresor 


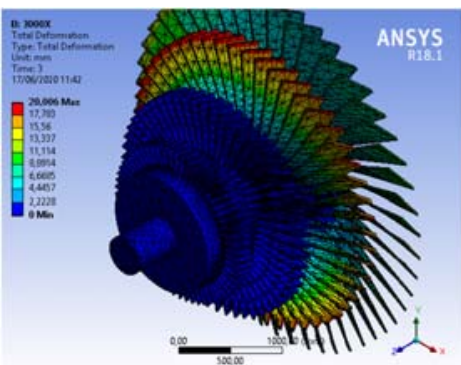

(a)

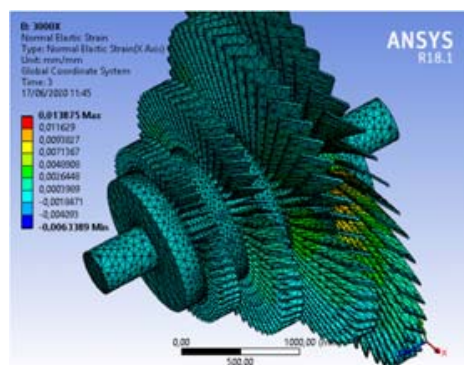

(b)

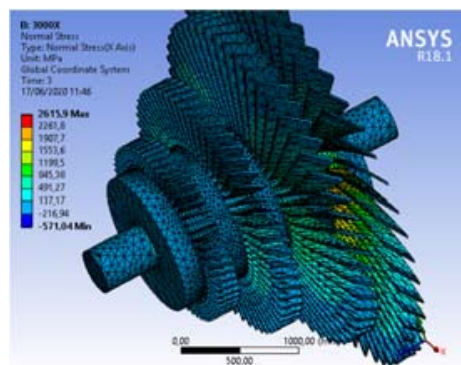

(c)

Gambar 4.2 (a) Total Deformasi (b) Regangan Normal (c) Tegangan Normal pada Arah Horizontal dengan Kecepatan 3000 rpm

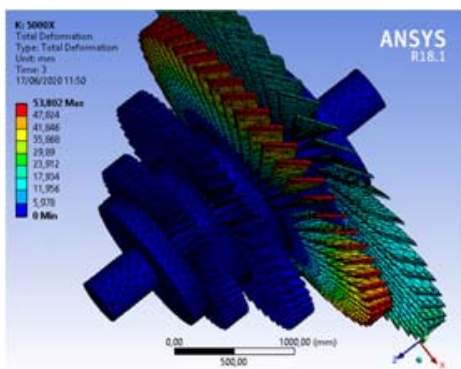

(a)

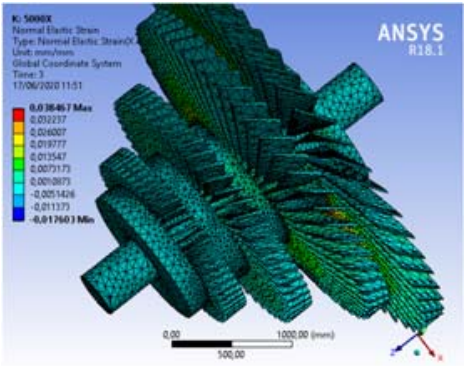

(b)

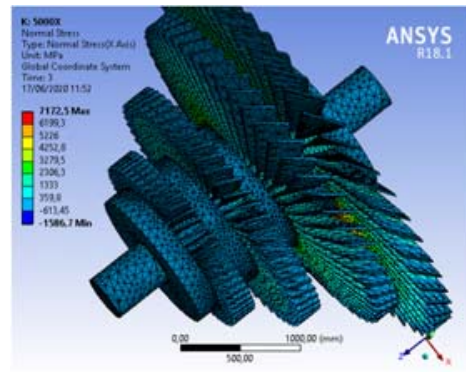

(c)

Gambar 4.3 (a) Total Deformasi (b) Regangan Normal (c) Tegangan Normal pada Arah Horizontal dengan Kecepatan 5000 rpm

Tabel 4.1 Hasil Simulasi Turbin Gas Empat Tingkat dengan Kecepatan 3000 rpm

\begin{tabular}{|l|c|c|c|}
\hline Kecepatan putar 3000 rpm & Horizontal & Vertikal & Aksial \\
\hline Total Deformation (mm) & 20,006 & 20,006 & 20,006 \\
\hline $\begin{array}{l}\text { Normal Elastic Strain } \\
(\mathrm{mm} / \mathrm{mm})\end{array}$ & 0,013875 & 0,013875 & 0,013875 \\
\hline Normal Stress (MPa) & 2615,9 & 2615,9 & 2615,9 \\
\hline
\end{tabular}

Tabel 4.2 Hasil Simulasi Turbin Gas Empat Tingkat dengan Kecepatan 5000 rpm

\begin{tabular}{|l|c|c|c|}
\hline Kecepatan putar 5000 rpm & Horizontal & Vertikal & Aksial \\
\hline Total Deformation (mm) & 53,802 & 53,802 & 53,802 \\
\hline $\begin{array}{l}\text { Normal Elastic Strain } \\
(\mathrm{mm} / \mathrm{mm})\end{array}$ & 0,038467 & 0,038467 & 0,038467 \\
\hline Normal Stress (MPa) & 7172,5 & 7172,5 & 7172,5 \\
\hline
\end{tabular}

Dari hasil pengujian statika diatas dapat dilihat bahwa pada putaran $3000 \mathrm{rpm}$ untuk semua arah (horizontal, vertical, dan aksial) beban lentur yang diberikan mendapatkan hasil 
total deformation yaitu 20,006 mm. Normal elastic strain yaitu $0,013875 \mathrm{~mm} / \mathrm{mm}$.Dan normal stress yaitu 2615,9 MPa.

Sedangkan dari hasil pengujian statika diatas dapat dilihat bahwa pada putaran 5000 rpm untuk semua arah (horizontal, vertical, dan aksial) beban lentur yang diberikan mendapatkan hasil total deformation yaitu 53,802 mm. Normal elastic strain yaitu 0,038467 $\mathrm{mm} / \mathrm{mm}$.Dan normal stress yaitu 7172,5 MPa. Hal ini terjadi Karena nilai dari beban lentur yang diberikan terlalu kecil, sehingga tidak mempengaruhi nilai dari tiap arah dari beban yang diberikan. Dari tabel pengujian diatas di dapatkan grafik sebagai berikut :

a. Grafik perbandingan hasil simulasi total deformation

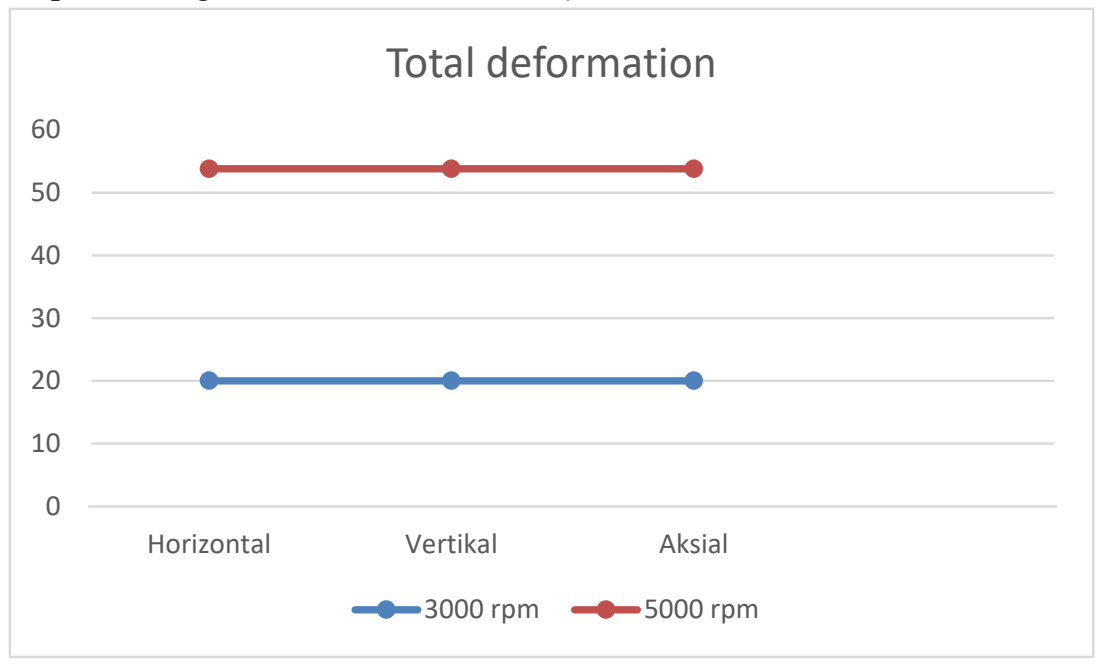

Gambar 4.4 Grafik Total Deformation

b. Grafik perbandingan hasil simulasi normal elastic strain

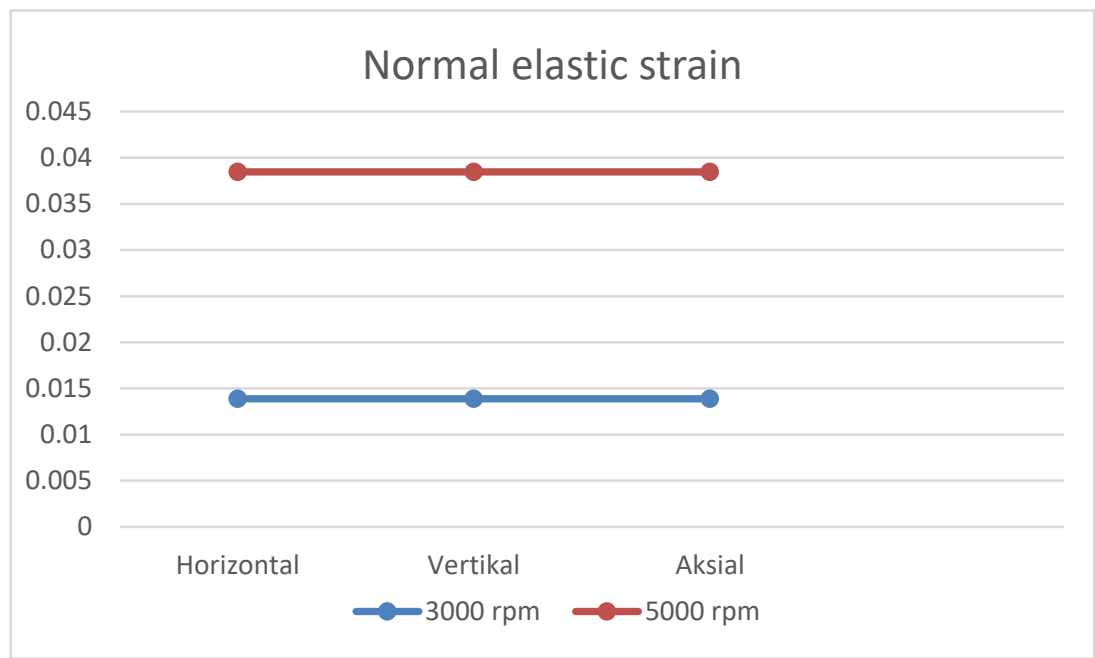

Gambar 4.5 Grafik Normal Elastic Strain 
c. Grafik perbandingan hasil simulasi normal stress

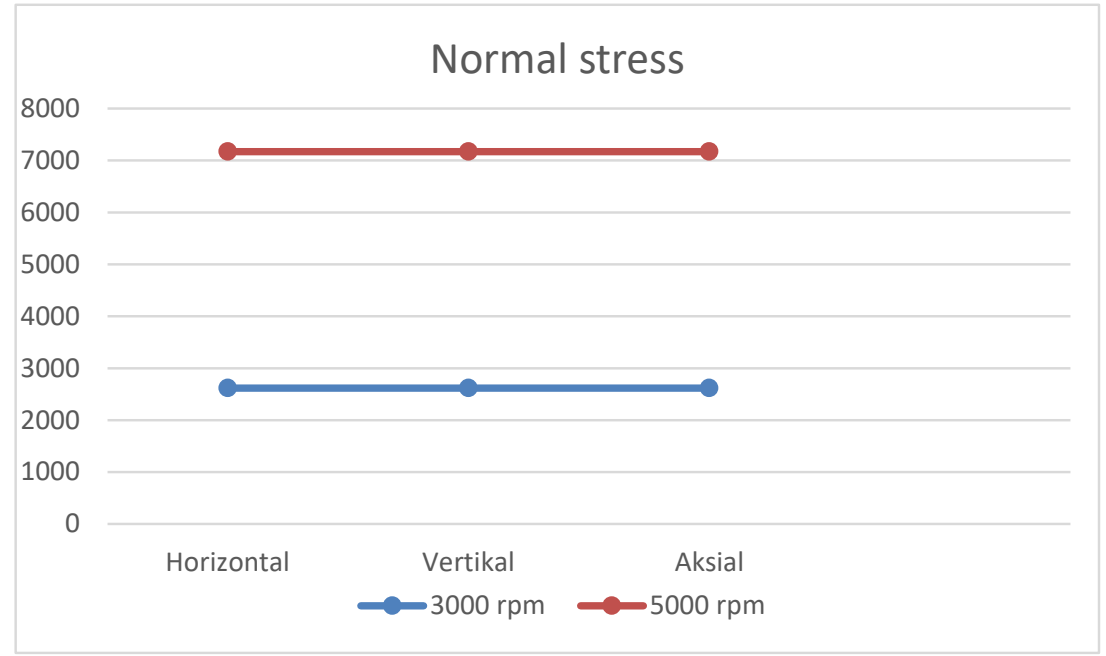

Gambar 4.6 Grafik Normal Stress

\section{KESIMPULAN}

Berdasarkan simulasi dengan menggunakan software ANSYS 18.1 turbin gas empat tingkat mendapatkan hasil pada putaran 3000 untuk semua arah (horizontal, vertical, dan aksial) beban lentur yang diberikan mendapatkan hasil total deformation yaitu 20,006 $\mathrm{mm}$. Normal elastic strain yaitu $0,013875 \mathrm{~mm} / \mathrm{mm}$.Dan normal stress yaitu 2615,9 MPa. Sedangkan pada putaran 5000 rpm untuk semua arah (horizontal, vertical, dan aksial) beban lentur yang diberikan mendapatkan hasil total deformation yaitu $53,802 \mathrm{~mm}$. Normal elastic strain yaitu $0,038467 \mathrm{~mm} / \mathrm{mm}$.Dan normal stress yaitu $7172,5 \mathrm{MPa}$

Nilai frekuensi natural pada ketiga sumbu hasilnya sama, frekuensi yang dihasilkan adalah yaitu 34,022 Hz; 47,739 Hz; 47,743 Hz; 48,672 Hz. Pada kecepatan putar 5000 rpm nilai frekuensi natural pada ketiga sumbu hasilnya sama, yaitu 37,537 Hz; 66,377 Hz; 66,406 Hz; $78,309 \mathrm{~Hz}$. Frekuensi kerja turbin gas pada kecepatan $3000 \mathrm{rpm}$ adalah $50 \mathrm{~Hz}$ dan pada kecepatan $5000 \mathrm{rpm}$ adalah $83,3 \mathrm{~Hz}$ sehingga aman dari frekuensi kritis turbin gas.

\section{REFERENSI}

[1] Arismunandar, Wiranto. 2002. Pengantar Turbin Gas dan Motor Propulsi. Bandung. ITB

[2] Didik, Djiki Susilo. 2009. Pemantauan Kondisi Mesin Berdasarkan Sinyal Getaran.. UNS

[3] Hamid Abdul. 2011. Praktikal Vibrasi Mekanik: Teori dan Praktik. Yogyakata: PT. Graha Ilmu

[4] Hardiyadi. 2009. Boiler dan Turbin. Bandung. Politeknik Bandung 
[5] Mott, Robert. L. PE. 2004. Elemen-elemen Mesin Dalam Perancangan Mekanis Edisi 4. Yogyakarta. ANDI

[6] Sularso dan Kiyokatsu Suga. 1991. Dasar Perencanaan dan Pemilihan Elemen Mesin. Jakarta: PT. Pradnya Paramita

[7] Thomson, Willian. T, Teori Getaran dengan Penerapan. Edsisi kedua. ITS. Surabaya

[8] Titherington, dkk. 1984. Mekanika Terapan Edisi Kedua. Jakarta: PT. Erlangga

[9] Tungga, BK. 2011. Dasar-dasar Getararan Mekanis. Yogyakarta. CV Andi Offset

[10] Y, Ramses Hutahean. 20022. Getaran Mekanis. Yogyakarta. CV Andi Offset 